\title{
Solar Trigeneration System Model for Off-Grid Residential Applications
}

\author{
Pedro Magalhães ${ }^{1}$, João Martins ${ }^{1}$, António Joyce ${ }^{2}$, Luís Coelho ${ }^{3}$, Nelson Tavares ${ }^{3}$, \\ and Ricardo Pereira ${ }^{2}$ \\ ${ }^{1}$ CTS/Uninova, DEE, Faculdade de Ciências e Tecnologia, Universidade Nova de Lisboa, \\ 2829 - 516 Caparica, Portugal \\ jf.martins@fct.unl.pt \\ ${ }^{2}$ Laboratório Nacional de Energia e Geologia, Estrada do Paço do Lumiar 22, \\ 1649 - 038 Lisboa, Portugal \\ antonio.joyce@lneg.pt \\ ${ }^{3}$ Escola Superior de Tecnologia, Instituto Politécnico de Setúbal, Campus do IPS \\ 2910 - 716 Setúbal, Portugal
}

\begin{abstract}
A solar trigeneration system for off-grid households, based on photovoltaic-thermal (PV/T) collectors, photovoltaic (PV) modules and a heat pump (HP), whose aim is to provide enough electricity, domestic hot water (DHW), heating and cooling power to meet the typical demand of an offgrid single family dwelling, is modeled to predict its performance, enable system sizing and evaluate the impact of different control and management strategies. The system integrates an autonomous photovoltaic system, a solar DHW system and a heating, ventilation and air-conditioning (HVAC) system. Thus, according to local climate data, construction elements, load profiles and storage dynamics, the model computes the system's net results using a simple supply and demand approach. Additionally, a design space methodology is used to evaluate system performance for different sizes and identify a feasible design region within which reliable and cost-effective system sizing is possible.
\end{abstract}

Keywords: Solar Trigeneration, Cooling, PV/T, Heat Pump, Off-grid, Model, SDHW, HVAC, Autonomous Systems, Residential Sector.

\section{Introduction}

Solar trigeneration systems are able to simultaneously generate electricity, heat and cooling power from solar energy. Among the solar trigeneration systems already devised, most feature absorption cycle chillers as the cooling equipment [1]. However, research has shown that electric-driven refrigeration has greater economic viability than absorption refrigeration for the residential sector [2],[3]. Additionally, absorption chillers have high temperature requirements and not all solar harnessing technologies are well suited to drive them, namely PV/T collectors, which are likely unable to provide such high temperature heat most of the year unless multiple glass covers are used, and whose PV laminate must be kept at lower temperatures to 
prevent damage to the laminate [4]. Thus, PV/T collectors are well suited to provide lower temperature heat for DHW while simultaneously providing electric power to drive cooling equipment. Among them, electric driven vapour compression (VC) refrigeration is deemed the most cost-effective for residential applications, due to among other factors, high efficiencies and a consolidated economy of scale [3]. Application of $\mathrm{PV} / \mathrm{T}$ collectors has been focused in grid-connected applications, mainly because these are seen as the main market for PV/T collectors [5]. However, use of PV/T collectors in autonomous systems has been reported in crop drying and solar distillation processes though not in the residential sector.

The aim of this article is to evaluate the potential of a solar trigeneration system for the off-grid residential sector based on PV modules, PV/T collectors and a VC heat pump by following the modeling methodology described in [6]. Additionally, a sizing methodology is used to determine which configurations are most suitable for reliable system operation.

\section{Contribution to Value Creation}

The present work is to contribute to value creation by highlighting tools and guidelines that can be used to understand and size off-grid solar trigeneration systems. Also, the methodology used in this article can be used to size a system which enables continuous operation for an off-grid dwelling, but can also be extended to other applications, which may differ in scope, scale and in the technologies used.

\section{System Configuration}

A simplified schematic of the proposed solar trigeneration system is illustrated on Fig. 1. The key components of the system are PV modules, PV/T collectors, an inverter, maximum power point tracking (MPPT) devices, a battery bank, an air-to-water vapor compression heat pump (HP) and thermal storage tanks (TST) for DHW (DHW-TST) and HVAC (HVAC-TST). Other system configurations are possible with these key components, though with different levels of complexity, parts and controls. This paper will focus on the simplest and most reliable configuration, which will serve as a background against which other options can be evaluated. In this regard, the HVACTST is optional and will increase initial costs, maintenance and installation space but it allows for increased flexibility, which may prove important to optimize system performance - by operating the HP during periods suitable for high efficiency operation and storing cold or hot water in the HVAC-TST for later use.

The PV modules and the PV/T collectors provide electric power to the loads, either instantaneously or via a storage element, enabling continuous system operation. The $\mathrm{PV} / \mathrm{T}$ collectors also provide power to the solar DHW system through a thermal storage tank, the DHW-TST. The heat pump unit provides and extracts heat to and from the household, respectively. The system power flow is illustrated on Fig. 2. 

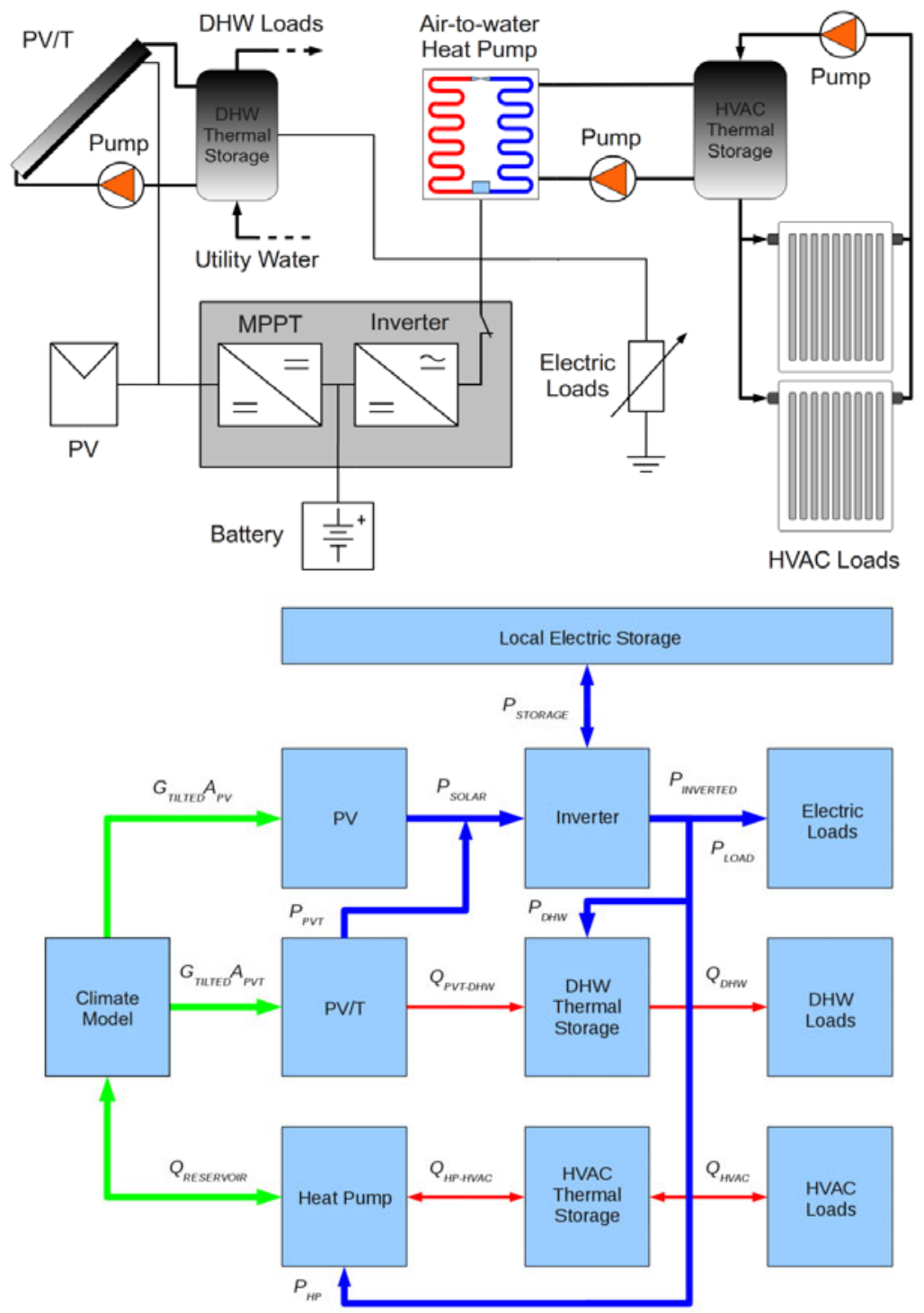

Fig. 1. Proposed system configuration: off-grid solar trigeneration system with HVAC-TST

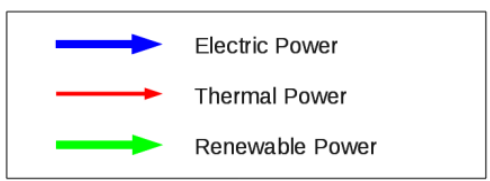

Fig. 2. Solar trigeneration system power flow diagram 


\section{System Model}

The system model is a tool for understanding and predicting the performance of the trigeneration system as well as sizing it. A definitive model is one that not only covers the most distinctive phenomena associated with a process, but also those believed to be secondary in nature. However, certain aspects of the system performance, which are deemed to be of secondary nature, can be ignored if properly justified according to the specified objectives. Regarding the proposed trigeneration system, the authors chose to ignore the transient performance of the electric system since it is highly dependent on the installation and quality of the components rather than system sizing. On the other hand, the transient performance of solar collectors and thermal storage tanks was not ignored since their combined performance is known to be decisively influenced by transient dynamics [7].

The system model was developed according to the methodology presented in [6] which consists on having three submodels - climate, building and trigeneration system - with various types of interactions. The system model was developed around MATLAB/SIMULINK, which integrates all system components whether or not these have been developed in MATLAB/SIMULINK - most were and a custom MATLAB/SIMULINK library was developed to accommodate them. The climate model uses input data from the SOLTERM software, a computer program which provides reference climate data for Portuguese municipalities, and the building model was mostly done using DesignBuilder, a building performance analysis software that complies with the ASHRAE 140-2004 standard as required under Portuguese legislation for Energy Efficient Buildings.

\subsection{Climate Model}

The climate model uses hourly reference outdoor temperatures and irradiation values on an horizontal surface to estimate other relevant climate variables, namely sky temperature and irradiation on a sloped surface, respectively. The isotropic irradiation model was used to determine the irradiation on a sloped surface, since it is known to provide the most conservative estimates.

\subsection{Building Model}

The thermal energy that must be provided to or extracted from the household in order to meet thermal comfort levels was estimated using DesignBuilder, which calculates these values in one hour steps according to climate data and occupancy schedules. DesignBuilder was also used to shape electric load profiles concerning lighting and domestic appliances. MATLAB/SIMULINK was used to model the remaining thermal (DHW load profiles) and electric loads (HP and DHW backup power).

\subsection{Trigeneration Model}

The outputs of the climate and building models are used as inputs of the trigeneration model, which acts as an energy conversion and storage model, while also containing several submodels. Among them are a PV array model, a PV/T collector array model, a TST model, a HP model, an electric battery model, various tunable controllers, a 
simplified steady state inverter model and cable losses estimation model. The models are arranged in a way so that the system power flow is exactly like the one displayed in Fig. 2. Brief descriptions of key component models are provided.

The inverter model, like all other components of the electric system, was developed according to a steady-state power based approach. The model uses readily available efficiency curves supplied by manufacturers, safeguarding maximum and minimum input power constraints.

The electric battery was implemented as a steady-state energy storage model as suggested by [8]. Thus, the model ignores the typical voltage-current model of batteries and instead focuses on energy storage irrespective of form while including different charging and discharging efficiencies and also self-discharge.

The HP model implemented is a steady state electric load using manufacturer supplied efficiency tables. This approach lacks the detail of more complex models but lessens the computational burden and allows users to easily evaluate different HP units because the model relies on readily available data.

The performance of PV modules was estimated using a steady state model based on the maximum power point, which decreases almost linearly with cell temperature. Hence, if the array is connected to a maximum power point tracking (MPPT) device, the model is valid and less computationally intensive than the single diode equivalent circuit model commonly used for transient rather than steady state simulations.

A single cover sheet and tube PV/T collector was modeled to determine the steady state and transient responses of the collectors using a set of one-dimensional energy balance equations, an adequate approach according to [7][9][10].

The thermal storage tank model must be effectively capable of reproducing stratification phenomena for it affects the performance of solar collectors [7]. The multi-node model presented in [11] was implemented due to its relative simplicity and completeness, which includes heat transfer to the surroundings, conduction from warm layers to cold layers, conduction through thermocline and thermal mixing.

\section{Simulation}

The proposed trigeneration system was simulated for a typical meteorological year (TMY) under Lisbon climate. However, the actual simulated setup is different from the one presented in Fig. 1 due to the omission of the HVAC-TST, which is optional and whose inclusion must be properly evaluated. Thus, the system is simulated without the HVAC-TST as a way to provide results against which improvements namely the inclusion of the HVAC-TST - can be evaluated.

\subsection{Parameters}

Lisbon is located at $38^{\circ} 42^{\prime} \mathrm{N}$ and $9^{\circ} 8^{\prime} \mathrm{W}$. The climate is considered to be SubtropicalMediterranean and temperatures range from $4^{\circ} \mathrm{C}$ up to $36^{\circ} \mathrm{C}$. Annual irradiation peaks at a south facing $30^{\circ}$ slope with the horizontal plane and is about $1600 \mathrm{kWh} / \mathrm{m}^{2}$.

Simulations were conducted on a single family dwelling, whose construction elements are in accordance with Portuguese building codes, for four occupants with 2 
floors, an attic and a total living area of $225 \mathrm{~m}^{2}$. The electric and DHW load profiles were set to resemble typical daily and annual consumption levels.

The PV/T collectors used for this simulation are $1.67 \mathrm{~m}^{2}$ single cover sheet and tube collectors whose thermal and electric efficiencies are displayed in Fig. 3, exhibiting maximum thermal and electric efficiencies of about $59 \%$ and $14 \%$.

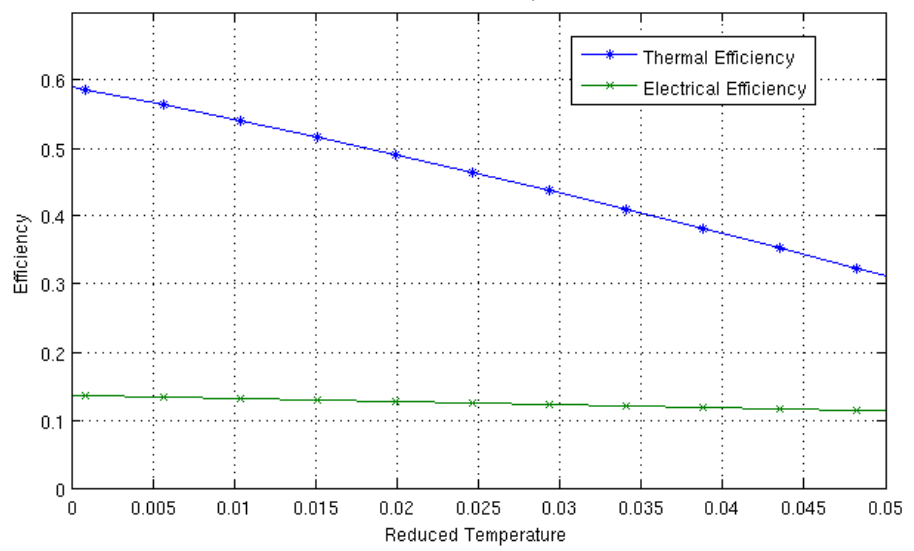

Fig. 3. Thermal and electric efficiencies of the single cover sheet and tube PV/T collectors

The solar DHW system was simulated with $6.68 \mathrm{~m}^{2}$ of PV/T collector area, a differential temperature controller with $10^{\circ} \mathrm{C}$ and $2^{\circ} \mathrm{C}$ thresholds for on and off modes, respectively, a specific flow rate of $10 \mathrm{Kg} / \mathrm{m}^{2} \mathrm{~h}$ and a TST model with three vertical nodes whose properties are specified in Table 1 . These values are typical and while the PV/T collector area is slightly higher than the $6 \mathrm{~m}^{2}$ of collector area used in [7],[10], the other parameters are common in residential solar DHW systems.

Table 1. DHW-TST parameter values

\begin{tabular}{cccc}
\hline Parameter & Volume $\left(\mathrm{m}^{2}\right)$ & Inner Surface Area $\left(\mathrm{m}^{2}\right)$ & Heat Loss Coefficient $\left(\mathrm{W} / \mathrm{m}^{2} \mathrm{~K}\right)$ \\
\hline Value & 0.2 & 2 & 1 \\
\hline
\end{tabular}

Regarding the HVAC system, a commercial air-to-water HP unit with adequate power rating was selected and set to produce cold water at $7{ }^{\circ} \mathrm{C}$ and hot water at $35^{\circ} \mathrm{C}$. Fan-coils were selected as the terminal HVAC units for the simulation.

The number of PV modules and the slope angle at which they are to be positioned for simulation purposes must be determined via comprehensive system sizing. Nonetheless, the parameters of the PV modules are displayed in Table 2.

Table 2. PV module parameter values under standard test conditions (STC)

\begin{tabular}{cccccc}
\hline Parameter & Area $\left(\mathrm{m}^{2}\right)$ & $\begin{array}{c}\mathrm{P}_{\text {rated }} \\
(\mathrm{W})\end{array}$ & $\begin{array}{c}\eta_{\text {module }} \\
(\%)\end{array}$ & $\rho(\%)$ & $\begin{array}{c}\mathrm{P}_{\text {rated }} \text { Temperature Coefficient } \\
(\mathrm{W})\end{array}$ \\
\hline Value & 1.67 & 230 & 13.78 & 87 & -0.38 \\
\hline
\end{tabular}




\subsection{Sizing}

A multi-variable design space sizing methodology, similar to the one presented in [8], was used in order to size the system according to design constraints. The purpose is to understand which combinations of PV module area, slope and battery size allow system operation without loss of load (LOL) occurrence while safeguarding the condition for multi-year operation, i.e., the battery's state of charge (SOC) after one year must be higher or equal to its initial value. A straightforward strategy was used to simplify this otherwise complex problem: the total PV area is divided into groups of PV modules with different slopes. Thus, production can be shaped to match demand throughout the year. The design space - displayed in Fig. 4 as a domain of system configurations within which adequate system operation is possible - was obtained for two PV groups, one of which is composed of 20 modules sloped at $30^{\circ}$ south, and relates battery size, slope and number of PV modules in the second group.

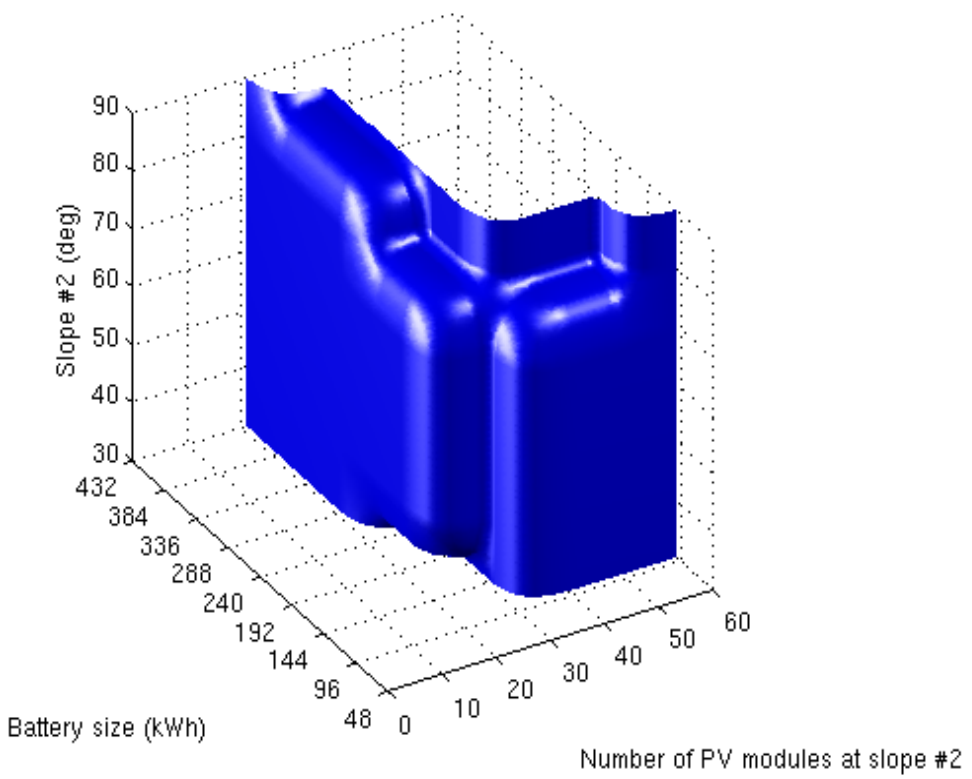

Fig. 4. Design space according to battery size, number of PV modules and slope angle of the $2^{\text {nd }} \mathrm{PV}$ group: beyond the surface the system is feasible, otherwise the system is unfeasible

The domain seen in Fig. 4 is mostly shaped by low photovoltaic generation and insufficient storage capacity, namely for combinations of low PV area and battery size. The design space is also shaped by climate data and load patterns. In this particular case, peak demand occurs during the Winter months and peak solar irradiation occurs during the Summer months, thus requiring large battery sizes if power is to be continuously supplied to the household throughout the year.

The design space suggests multiple possible system sizes though additional constraints, namely cost, can help narrow down the feasible options. The battery is purportedly the most sensitive component, namely with regard to cost per $\mathrm{kWh}$ and lifetime. However, increasing the number of PV modules to decrease battery size also 
increases the battery rating, thus also increasing the cost. A simple compromise is to select the lowest possible battery size and the lowest possible array area - as seen in Fig. 5.

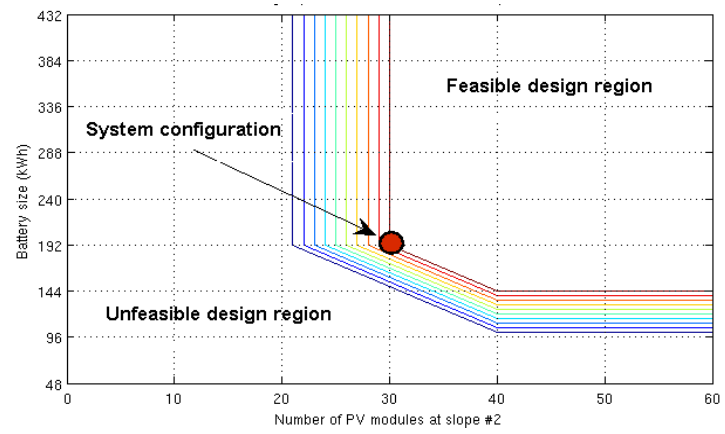

Fig. 5. System design space according to battery size and number of PV modules at the $2^{\text {nd }}$ group for a slope angle of $60^{\circ}$ - the plot is a horizontal slice of Fig. 4

A system comprising $20 \mathrm{PV}$ modules in the first group $\left(30^{\circ}\right), 30 \mathrm{PV}$ modules in the second group $\left(60^{\circ}\right)$ and a battery size of $192 \mathrm{kWh}$ was determined as reliable and cost-effective according to the strategy outlined earlier. The battery required for the aforementioned system must have a minimum power rating of $11520 \mathrm{~W}$ or $240 \mathrm{~A}$ at $48 \mathrm{~V}$, in order to be able to absorb the combined power of the PV modules and PV/T collectors under minimum temperature conditions - i.e., a conservative constraint.

\subsection{Results and Analysis}

The building simulation revealed that the annual thermal energy demand to reach comfort levels amounts to $4842 \mathrm{kWh}$ of energy that must be provided to the household and $1552 \mathrm{kWh}$ of energy that must be extracted from the household. Fig. 6 shows displays the heat transfer requirements for thermal comfort in one hour steps.

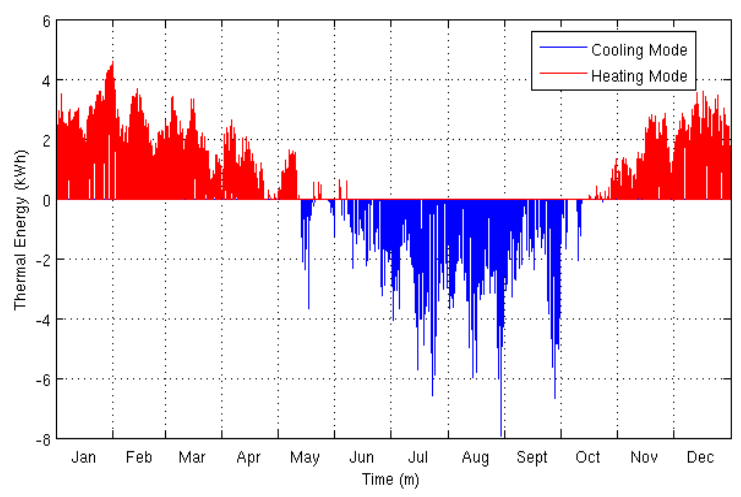

Fig. 6. Thermal energy to be provided to (red) and extracted from (blue) the household 
According to the simulation results, the HP operates at annual average efficiencies of 4.25 in heating mode and 3.5 in cooling mode, requiring a total of $1595 \mathrm{kWh}$ of electricity annually - the annual simulation results are displayed in Table 3.

Table 3. Annual simulation results for the proposed trigeneration system

\begin{tabular}{cc|cc}
\hline Production & Energy $(\mathrm{kWh})$ & Demand & Energy $(\mathrm{kWh})$ \\
\hline Electric Production (DC) & 8228 & Electric Demand (AC) & 6179 \\
- Waste & 10446 & - Heating & 1152 \\
- Ohmic Losses & 111 & - Cooling & 443 \\
- PV & 7966 & - DHW Backup & 1242 \\
- PV/T & 485 & - Lighting & 1102 \\
Electric Production (AC) & 6179 & - Appliances & 2240 \\
\hline
\end{tabular}

The solar DHW system performs well, reaching a solar thermal fraction of $65 \%$. The PV/T collectors generated $1643 \mathrm{kWh}$ of thermal energy at an average efficiency of about $15 \%$ compared to $24.3 \%$ in [7], which is best explained by the backup system used. The aspects affecting thermal performance are explained in detail in [6].

The bulk of photovoltaic production is due to the PV modules rather than the PV/T collectors, due to lower collector areas and generally higher absorber temperature. In any event, photovoltaic production is marred by considerable waste of solar power due to the inability to charge the battery beyond its rated capacity during the Summer.

The battery size is considerably large but within standard figures with regard to the days of average consumption it can withstand without being charged, in this case about 11 days - according to [12] it should typically be between 3 and 20 days. The battery SOC after one year $-87 \%$ - is considerably higher than its initial value $-75 \%$ - which means the system is feasible and also that, if battery lifetime considerations are ignored, system performance is likely to improve after the first year.

\section{Conclusions}

A model of the proposed trigeneration system based on PV modules, PV/T collectors and a HP has been developed and simulated. The design space obtained for the system shows that the system is feasible though costly. This is due, in part, to the domestic load profile selected, which reflects traditional, i.e. grid-connected, load profiles. Also, the model enabled a deeper understanding of the limitations of solar technology if peak demand occurs during low irradiation months, thus suggesting the need for seasonal energy storage or an alternative energy source for Winter months. Future research will focus on improving existing models and establishing detailed cost functions to avoid waste and ensure cost-effective system sizing.

Acknowledgments. The authors would like to thank ENERGIA PRÓPRIA S.A. and the Portuguese QREN (2007-2013) program for proposing and funding the SOL3 project (QREN reference 2010/12516). 


\section{References}

1. Al-Sulaiman, F.A., Dincer, I., Hamdullahpur, F.: Exergy modeling of a new solar driven trigeneration system. Solar Energy 85, 2228-2243 (2011)

2. Fong, K., Chow, T., Lee, C., Lin, Z., Chan, L.: Comparative study of different solar cooling systems for buildings in subtropical city. Solar Energy 84, 227-244 (2010)

3. Immovilli, F., Bellini, A., Bianchini, C.: Solar trigeneration for residential applications, a feasible alternative to traditional micro-cogeneration and trigeneration plants. In: Industry Applications Society Annual Meeting, pp. 1-8. IEEE (2008)

4. Dupeyrat, P., Menezo, C., Rommel, M., Henning, H.: Efficient single-glazed flat plate photovoltaic-thermal hybrid collector for domestic hot water system. Solar Energy 85, 1457-1468 (2011)

5. Zondag, H.: Flat-plate PV-Thermal collectors and systems: A review. Renewable and Sustainable Energy Reviews 12, 891-959 (2008)

6. Joyce, A., Coelho, L., Martins, J., Tavares, N., Pereira, R., Magalhaes, P.: A PV/T and Heat Pump based Trigeneration System for Residential Applications. In: Proceedings of the ISES Solar World Congress 2011, Kassel, Germany. ISES, Freiburg (2011)

7. Santbergen, R., Rindt, C., Zondag, H., Zolingen, R.: Detailed analysis of the energy yield of systems with covered sheet-and-tube pvt collectors. Solar Energy 84, 867-878 (2010)

8. Arun, P., Banerjee, R., Bandyopadhyay, S.: Sizing curve for design of isolated power systems. Energy for Sustainable Development 11, 21-28 (2007)

9. Zondag, H., de Vries, D., van Helden, W., van Zolingen, R., van Steenhoven, A.: The thermal and electrical yield of a pv-thermal collector. Solar Energy 72, 113-128 (2002)

10. Silva, R., Fernandes, J.: Hybrid photovoltaic/thermal (PV/T) solar systems simulation with SIMULINK/MATLAB. Solar Energy 84, 1985-1996 (2010)

11. Nelson, J., Balakrishnan, A., Murthy, S.S.: Parametric studies on thermally stratified chilled water storage systems. Applied Thermal Engineering 19, 89-115 (1999)

12. Mulder, G., De Ridder, F., Six, D.: Electricity storage for grid-connected household dwellings with PV panels. Solar Energy 84, 1284-1293 (2010) 